\title{
Socio-Cultural Sphere, Governance and City Branding in New Economy
}

\author{
Vadim Yurievich Pashkus ${ }^{1}$, Natalia Anatolievna Pashkus ${ }^{2}$, Asadula Badrutdinovich Asadulaev ${ }^{1} \&$ Anna Olegovna \\ Bulina $^{1}$ \\ ${ }^{1}$ Faculty of Economics, Saint Petersburg State University, Saint Petersburg, Russian Federation \\ ${ }^{2}$ Department of economics, Herzen State Pedagogical University of Russia, Saint Petersburg, Russian Federation \\ Correspondence: Vadim Yurievich Pashkus, Universiteckaja nab. 7/9, Saint Petersburg, 199034, Russian \\ Federation
}

Received: February 28, 2015 Accepted: March 20, 2015 Online Published: April 24, 2015

doi:10.5539/res.v7n6p86 URL: http://dx.doi.org/10.5539/res.v7n6p86

\begin{abstract}
The article analyzes the problems of socio-cultural sphere in the new economy, as well as the impact of socio-cultural sphere on the brand of St. Petersburg, paper also discusses possibility of evaluation of changes in brand strength due to socio-cultural impact. The proposed method of estimation of the strength of the brand is universal enough, but due to a pronounced specificity of various segments of the public sector it requires specifying when evaluating consumer interest in services for various types of organizations. In this paper, brand evaluation can not be based on the financial performance of organizations; we are not interested on the characteristics of brand equity, but on indicators of consumer preferences and the associated strength of the brand on the market. The proposed method can be adapted to different segments of the public sector (and their impact on brand site) that require adaptation indicators of demand and availability of the services of these organizations. It requires considering not only the classical estimation of the brand, calculated using the method of The Boston Consulting Group (BCG) including adaptation of its indicators for socio-cultural sphere, and together with the emotional evaluation of brand strength by Keller (Keller, 2005) used to calculate the integral market power of the brand. Priority of emotional components is defined by specific traits of Russian market in general and the cultural market, in particular. The competitiveness of the regional institutions of socio-cultural sector and the strength of their brand directly affects the competitiveness of the region as such. The paper raises questions of so called "star" status and orientation on brands in risk conditions. Brand allows city to start the process of urban regeneration, become the basis of its development strategy, and to revive the use of vacant spaces as well. Branded cities attract not only tourists but also entrepreneurs in various industries, people who want to live interesting, in an unique location and have access to the benefits of modern goods, unique heritage, objects and experiences. Brand adds a certain "flavour" to the city. It can be promoted; it can attract the most qualified workers not only with competitive salary and benefit packages, but with a good place for work and for pleasures as well.
\end{abstract}

Keywords: socio-cultural sphere, new economy, cultural institutions, brand of St. Petersburg, strength of the brand (by Keller), brand of the territory, Y \& R method

\section{Introduction}

In modern conditions a balanced development of the regions of Russia and its investment attractiveness requires the formation of a comprehensive strategy that takes into account not only the economic and natural features of the region but also crucial characteristics of its human resources. At the regional level human resources determine the frame of personnel and business potential of the region and, consequently, their strategic options, as well as characteristics of the consumer market (Vertakova et al., 2013). Thus, the quality of human resources in the region depends on economic potential of that very region.

At the same time the quality of human resources is provided by public sector. Institutions of the sector carried out the formation of human resources by the means of education, health care, cultural development. Quality of human resources depends on the quality of public sector institutions and services for the population of the region. If a national brand, according to (Potter, 2009) is a kind of national soft power, such a soft power of metropolis is manifested at the state level (lobbing), and internationally. There is the competition among cities at various 
international markets from tourism to financial investment.

Simultaneously, "changes in the internal structure of national economies, the development of new functional connections and changes in the quality of interaction between the elements of these systems contribute to a creation of qualitatively new relations in the economy" (Pashkus, 2007). The classic structure of the public sector and classic approaches to ensure competitiveness of organizations in this sector are not applicable in the new economic conditions. The public sector cannot cope with assigned duties and does not correspond to the functional requirements of the new economic environment in which factors of uncertainty and risk have very high impact. What should be changed in the governance of socio-cultural sphere in order to match the new realities?

\subsection{Challenges of the New Economy}

New economic conditions can be characterized in terms of high dynamics of the environment, the requirements of highly innovative, customer-oriented, adaptive organization and shift towards services and the increasing importance of intangible assets.

To ensure adequate level of competitiveness in the new economy institutions of cultural sector should be given special attention to the following (Pashkus, 2012):

1) New tools for development of resource potential,

2) Identify the core competencies of public sector organizations and the formation of strategies based on these competencies;

3) Application of new tools of image formation for public sector institutions, building and strengthening their brands;

4) Modern tools of analysis and management in condition of risk and uncertainty;

5) Human resource management;

6) Information support of the organization and the formation of a unified information space with partners and consumers of public services;

7) Use of new financial mechanisms of the institutions and mechanisms providing access to public services;

8) Formation of integral systems in the public sector.

Application of these instruments is only possible after the systematic and comprehensive analysis of the internal and external environment of the organization, the study of dynamic characteristics of its competitive environment, as well as the study of the dynamics of social, institutional and public priorities that have an indirect impact on the competitiveness and the ability of public sector organizations.

Additional risks associated with new economic environment require more in-depth analysis and detailed models (Klieštik et al., 2014). It may include special attention towards financial risks (Gavlaková et al., 2014) as well as attention to interaction between government and business (Vertakova \& Plotnikov, 2013).

At the same time, even in a highly competitive economy, the public sector is usually weaker than commercial, as its activities are controlled by the conflicting requirements of government and public priorities, means of financial and organizational prosperity. Often these priorities come into considerable controversy among themselves. Public priorities should focus on the real quality of services but organizational and financial priorities focus on perceived quality. State requirements for the public sector often contain considerable controversy themselves since they form strategic priorities but do not contain actual implementation mechanisms, and sometimes the legislative level would prevent the implementation of mechanisms to achieve these priorities. In compliant with the individual characteristics of institutions and competitiveness, these organizations are to a greater or lesser extent independent and, consequently, to a greater or lesser extent ignore the existing contradictions. It turns out that to enter the high base level of competitiveness in the public sector it is considerably more complicated than in the commercial, but also in its position as the leading cluster is much more stable, even in the new economic conditions.

Strongly competitive in relation to public sector institutions have a significant weight in the implementation and feedback, as their competitive potential has a more significant impact on the competitiveness of the entire cluster, and the competitiveness of the region and the country. It should be noted that the impact of individual strengths in public sector is stronger in the region and the country, but not on cluster of organizations in this very sector. This can be observed by assessing the impact of strong institutions of social-cultural sphere (museums, theaters, universities) on the development of the regional economy and national economic system, taking into account 
their competitiveness. The very presence of strong regional cultural institutions allows the creation of the unique sources of competitive advantages around them. It can be a consortium of researchers and businesses, integrating innovative processes in the region (Rybakov, 2011) or a unique tourist complex (Social and cultural sphere, 2009). It ultimately contributes to the region's competitiveness in general.

\subsection{More or Less Powerful Brand}

All cultural institutions can be classified by the degree of brand awareness (Social and cultural sphere, 2009). Thus, so-called "theory of stars" could be applied (Frey, 2003). Already developed, existing and, especially, the "star" institutions have the greatest support, although support and development of the novice, young art is postulated. "Star" level often corresponds with the dominant taste or even tastes of the elite; it is usually developed by inertia, as targeted at preservation of their tastes rather than a breakthrough, experimental development. These cultural institutions have certain reputation that serves as an assurance of quality for potential customers, and therefore, protects them from facing risks of new but poor quality. But what can determine the "star" level of a city or an area?

As noted in (Frey, 2003), consumers of cultural goods do not agree to replace the more famous star with lesser known and presumably less talented performer even at a significantly lower price. It can be explained by dissemination of information about the outstanding performers and artists, the social component of the consumption of cultural services, as well as the limited cognitive abilities, expressed primarily in the inability to remember a large number of names of artists and to correlate with features of their creative properties .Features of star status found not only in individual artists but in whole institutions. Museums, theaters or opera houses may also have an outstanding status, because of which they would be a preferable alternative worth long distance travel (this case stardom can act as a basis for tourism). With the "star" level and brand cultural organizations attract more attention from visitors as well as the money (not only the authorities but also from patrons).

But not only by individuals, groups or cultural institutions are special or attractive, even phenomena as complex as the city may, in fact, can be a star on some markets. Territories can have bands and competitive advantages. There are examples of brand developed organically like Holy City of Jerusalem or established global brand of Casino-City of Las Vegas. This trend finds its confirmation in Johannesburg's brand program created by Interbrand (Joburg gains a brand, 2014) and many others.

Possible approaches include evaluation of the impact of socio-cultural sphere on brand of the city. The proposed method of estimation of the strength of the brand is universal enough, but due to a pronounced specificity of various segments of the public sector it requires specifying when evaluating consumer interest in services for various types of organizations. The proposed method can be adapted to different segments of the public sector (and their impact on brand site) that require adaptation indicators of demand and availability of the services of these organizations.

\section{Methods}

The proposed method of estimation of the strength of the brand is universal enough, but due to a pronounced specificity of various segments of the public sector it requires specifying when evaluating consumer interest in services for various types of organizations. In this paper, brand evaluation cannot be based on the financial performance of organizations; we are not interested on the characteristics of brand equity, but on indicators of consumer preferences and the associated strength of the brand on the market. The proposed method can be adapted to different segments of the public sector (and their impact on brand site) that require adaptation indicators of demand and availability of the services of these organizations. It requires considering not only the classical estimation of the brand, calculated using the method of BCG (including adaptation of its indicators for socio-cultural sphere), and together with the emotional evaluation of brand strength by Keller used to calculate the integral market power of the brand. Previously modifications of this method were approbated during research on competitiveness of the university through the strategic and image component (Pashkus \& Pashkus, 2013)

But before we move on to developing a specific methodology and justification of its benefits, it is necessary to dwell on the interpretation adopted in the literature terms methodological apparatus of brand evaluation. Russian researches on branding use the term "brand value". Unfortunately, there is no consensus about what brand value is, moreover, the term "value" is an integral concept is rather the consequence of an incorrect translation into Russian, which would make sense to treat rather as "capital". Due to the existing terminological confusion brand valuation became a clear financial question that seems unreasonable because of the emotional essence of the brand. In this regard, consideration of non-financial component of the brand remains outside the now classic approaches to brand evaluation, such as the BCG method (Lowy \& Hood, 2004). 
Brand evaluation cannot be based on the financial performance of organizations; we are not interested in the characteristics of brand equity, but in indicators of consumer preferences and the associated strength of the brand on the market. In this context, the proposed methodology will be more focused on the identification and evaluation of these particular characteristics.

\subsection{How Can the Strength of the Brand Be Evaluated}

It requires to consider not only the classical estimation of the brand, calculated using the method of BCG (including adaptation of its indicators for socio-cultural sphere), together with the emotional evaluation of brand strength by Keller, used to calculate the integral market power of the brand. Integration of classical estimates shall be based on the basic features of the techniques. Adaptation of BCG is necessary due to the fact that the classic version operates solely financial performance indices (profit, risk, etc.). This technique has a problem of brand overestimation that promotes the growth of error result that would exist in the absence of counter competitors that is in a market with low competition or brand valuation explicit market leader. An estimation based on Keller technique gives understated brand strength as it considers the emotional and sensual performance, largely responsive to targeted opposition from competitors. Thus, it seems reasonable to create an integral index, as average value of the estimations obtained by the above mentioned modified techniques.

Applying weighting coefficients in the construction of an integrated index of brand strength seems reasonable for correction indices calculated using classical techniques. Selection of specific weighting factors is conducted by the authors. The selection is based on the methodologies of qualitative ranking. Due to some overstatement of market power of the brand by the method of BCG and some underestimation of the emotional component of brand strength by Keller was made a priority in favor of emotional evaluation (weight 0.6) against financial evaluation (weight 0.4 ). Priority of emotional components is defined by specific traits of Russian market in general and the cultural market, in particular.

Applying the methodology created by Young \& Rubicam (Y\&R) in the structure of the authors' methodology allows considering the multidimensionality of brand. This technique allows to include in the analysis a par with the evaluation of brand strength is also assessing the merits of the brand, which is a reflection of the perceived market and consumers (including competitors and stakeholders) brand characteristics. In accordance with the Y\&R's procedure we have the opportunity not only to assess the quantitative characteristics of the brand, but also to identify whether brand belongs to a particular group of successful "stars" or not, as well as to create a strategy for the development of brand of territory (with a focus on the socio-cultural sector).

\section{Results}

For the evaluation of the brand within the BCG methodology these basic indicators are crucial (Poezhzaev, 2006):

1) M 1 (To sell it's more) - Indicator defining brand's contribution to the growth dynamics of development and financial situation of the territory in relation to a similar «unbranded» territory. This indicator measures how brand improves the financial position of the territory.

2) M 2 (To sell more expensively) - Indicator defining brand's contribution to increasing the profitability of its activities in relation to the specific expenses for the maintenance of the brand. This figure is to evaluate how the brand provides a growth of financial indicators.

3) M 3 (It's more than prospects) - Indicator that determines the possibility of brand extension and the expansion of its target segments in the medium term, this indicator allows to estimate how much more cash flows from the brand can be increased in the future.

Total cost estimate with BCG technique: $\mathrm{Ms}=\mathrm{M} 1 * \mathrm{M} 2 * \mathrm{M} 3$.

Indicator M 1 includes three main components. The first is the pushing force of the brand (PFa), which is calculated as the ratio of the integral characteristic activities of branded territory to the level of the integral characteristics of similar territory without the brand.

The second component of the index M1 is the pulling power of the brand (PFt), which is estimated as the ratio of growth indicators of the territory in the previous period in relation to the standard that is not caused by the growth of the brands more attractive to consumers. The third component of the index M1s the pulling force of the brand (PFbr), which is measured as the difference in the change of the integral characteristics of the brand and the standard site for the previous period of time.

Due to the fact that the two components are the first relative indices, and the last part era absolute, for calculating the $\mathrm{M} 1$ is advisable to use a relative pulling force of the brand (RFbr): 
$\mathrm{M} 1=\mathrm{RFbr}=(\mathrm{PFa}+\mathrm{PFt}+\mathrm{PFbr}) /(\mathrm{PFa}+\mathrm{PFt})$

The second indicator of brand valuation M 2 includes an estimation of the higher profitability of the brand relative to the standard site. This figure includes a premium for the brand (PB) and the marginal costs of brand's creation and promotion (MCB).

Marginal costs are calculated as the brand's total costs for the creation, development, positioning and brand promotion per citizen.

Thus the second component is equal to: $\mathrm{M} 2=\mathrm{PB} / \mathrm{MCB}$.

The third indicator of brand strength assessment determines the strategic competitiveness of the brand. The indicator defines the possibility of increasing the influence of the brand and the expansion of its target segment in the medium term, taking into account other risks. It makes possible to estimate how popularity and attractiveness of the area, as well as additional cash flow from the operation of the city from its brand in the future could increase.

Thus, the application of this technique will allow a comparative study and quantify the impact of socio-cultural sector on the brand of St. Petersburg.

\section{Discussion}

St. Petersburg's brand is promoted actively in Russia. Petersburg announces itself as a "cultural capital" of Russia; it can be a base for brand concept. Cultural capital (of capital of culture) needs developed cultural sector, in order to satisfy the declared image. Various actions at various levels have been made, but these means are not coordinated and often have a short-term nature (despite a decent enough budget) as long-term programs are declarative or populist. It seems that the understanding of the necessity of cultural development in the "cultural capital" is reduced to the formula "must be so, it is a tradition". In fact, the social and cultural sector itself, and in combination with a strong cultural brand have a significant impact on the economy. Culture and art are considered as alternative investment (Pashkus, 2013), cultural and art stage of the city can be considered as alternative tools of economic policy in face of modern day challenges. This concerns not only the tourism industry, but also investment (development of investment attractiveness of the city and region) and many other industries and sectors. Through the analysis of various international cases, it becomes obvious that the diversity of opportunities opens economy with a balanced approach to the development of the city or territory.

The brand of Petersburg for foreign guests (to some extent also for visitors from Russia and CIS) is clearly defined. It is based on the association with open-air museum, the city preserved but not developing. Hermitage's Director Mikhail Piotrovsky disputes position that "St. Petersburg is a city-museum, and the museums are not suitable for life" and "Life in the museum is not so bad!" (Piotrovsky, 2007).

Methods of comparison for brands of cities are developing by several companies such as Moody's, Saffron, Interbrand, PricewaterhouseCoopers (Cities of Opportunity, 2012), etc. Moody's ratings are credit ratings (Valášková, 2014), Saffron evaluates brand of the city using indirect approach.

"City Brand Barometer" (Hildreth, 2011) is a study conducted by the British agency Saffron, it evaluates urban brand strength by the following four factors: the number and power of positive and pleasant associations (25\%), recognition of landscape or cityscape - postcard test (25\%), value in the conversation (25\%), media coverage $(25 \%)$. The strength of the asset based on seven characteristics: Sights and historic attractions (20\%), cuisine and restaurants $(15 \%)$, if it is easy to explore on foot or by public transport $(15 \%)$, prices $(10 \%)$, weather $(10 \%)$, shopping (10\%), economic prosperity (20\%). There are no Russian cities in this study, but estimation of position of Saint-Petersburg with the proposed parameters is possible.

Interbrand views brands as financial asset for commercial brands, we can speculate whether its urban brand evaluation uses this approach. It shows that our modified methodology is consistent with main approaches as articulate and well-defined.

\section{Conclusion}

One can assume that the cultural sector has an influence on factors of production, and directly related sectors of human activity. Cultural sector creates jobs and tax revenue flows, attracts tourists, and stimulates the development of the surrounding businesses (not only the artists themselves or specialized manufacturers, but also a huge number of others: builders, manufacturers and sellers, managers and cleaners). Cultural sector influences the aspect of quality of life, it links generations through heritage and art.

Developed socio-cultural sector has a positive effect on the investment attractiveness of the region, as it allows creating of an environment conducive for harmonious economic relations of all market actors. Thus, the 
competitiveness of the regional institutions of socio-cultural sector and the strength of their brand directly affects the competitiveness of the region as such.

Cultural sector in modern conditions can work as a locomotive carrying out of the crisis on the local level .Often cultural organizations really need not so much the money, but the institutional environment: well developed regulations. There are many examples of the transformation from cities with closed main city-forming enterprise into the cultural centers on both local and international level. Brand allows city to start the process of urban regeneration, become the basis of its development strategy, and to revive the use of vacant spaces as well. This includes maintenance of villages and settlements, including the creation of jobs and leisure facilities as alternative to alcohol.

Branded cities attract not only tourists but also entrepreneurs in various industries, people who want to live interesting, in an unique location and have access to the benefits of modern goods, unique heritage, objects and experiences. Brand gives a certain "flavour" to the city. It can be promoted; it can attract the most qualified workers not only with competitive salary and benefit packages, but with a good place for work and for pleasures as well.

The study showed a modified methodology to assess "cultural" brand based on valuation techniques created for commercial brands. Despite the presences of certain flaws and availability of alternative methods, this technique is of interest as useful criteria for city managers and policy-makers.

For the general approbation of this technique it is necessary to conduct a comparative study on groups of cities, for which cultural component will have a different impact on the brand.

Socio-cultural sphere should be one of the focal points of regional economic policy. Introduction of new tools and development of new opportunities allow policy-makers to actively develop its role in the economy of the city. However, not all organizations in socio-cultural sphere are able to perceive new management techniques, not all have (or can draw) key employees. What is the basis for the differentiation of social and cultural facilities in St. Petersburg? The answer to this question is quite simple — branding.

\section{References}

Cities of Opportunity. (2012). Pricewater house Coopers LLP. Retrieved from http://www.pwc.com/us/en/cities-of-opportunity/index.jhtml

Frey, B. S. (2003). Arts \& Economics. Analysis \& Cultural Policy. Berlin: Springer-Verlag. http://dx.doi.org/10.1007/978-3-540-24695-4

Gavlaková, P., Valášková, K., \& Dengov, V. (2014). Credit Risk and its Evaluation. ICESS 2014, 2nd International Conference on Economics and Social Science (pp. 104-108). Shenzhen, China: Information Engineering Research Institute, Delaware USA

Hildreth, J. (2011). The Saffron European City Brand Barometer. Revealing which cities get the brands they deserve. Retrieved from http://www.macrame.tv/storage/Saff_CityBrandBarom.pdf

Joburg gains a brand. (2014). In Official Website of the City of Johannesburg. Retrieved November 30, 2014, from http://www.joburg.org.za/index.php?option=com_content\&task=view\&id=407\&Itemid=52

Keller, K. L. (2005). Strategic brand management: creation, assessment and management of branded capital. Moscow: Williams.

Klieštik, T., Lyakin, A. N., \& Valašková, K. (2014). Stochastic Calculus and Modeling in Economics and Finance. ICESS 2014, 2nd International Conference on Economics and Social Science (pp. 161-167). Shenzhen, China: Information Engineering Research Institute, Delaware USA.

Lowy, A., \& Hood, P. (2004). The power of the $2 x 2$ matrix. San Francisco: "Jossey-Bass".

Pashkus, M. V. (2013). Investments in Art: Opportunities and Challenges. Marketing MBA. Journal marketing management firms, 7(2), 196-214.

Pashkus, N. A. (2007). Innovative education reforms in Russia: Research methodology, estimation of efficiency and risk (Abstract of doctoral dissertation). St. Petersburg, Russia: Herzen State Pedagogical University.

Pashkus, V. Y. (2012). Competitiveness of public sector in the new economy (for example, universities) (Doctoral dissertation). St. Petersburg, Russia: Saint-Petersburg State University.

Pashkus, V. Y., \& Pashkus, N. A. (2013). Approaches to evaluating the Competitiveness of the University through the strategic and image component. Strategic management, 1, 54-68. 
Piotrovsky, M. B. (2007). View from the Hermitage. City Museum? This is a good and profitable. St. Petersburg Vedomosty.

Poezhzaev, K. (2006). Evaluating the effectiveness of the brand by identifying its impact on the financial results of the company. Retrieved from http://www.4p.ru/main/theory/1940/

Potter, E. H. (2009). Branding Canada: Projecting Canada's Soft Power through Public Diplomacy (pp. 1-345). McGill-Queen`s Universitety Press.

Rybakov, F. F. (2011). Industrial policy: Innovation and investment components. Innovations, 2, 77-82.

Social and cultural sphere: nature, structure and trends. (2009). St. Petersburg: OTsEiM.

Valášková, K., Gavlaková, P., \& Dengov, V. (2014). Assessing Credit Risk by Moody's KMV Model. In ICESS 2014, 2nd International Conference on Economics and Social Science (pp. 40-44). Shenzhen, China: Information Engineering Research Institute, Delaware USA.

Vertakova, Yu. V., \& Plotnikov, V. A. (2013). Russian and Foreign Experience of Interaction Between Government and Business. World Applied Sciences Journal, 28(3), 411-415.

Vertakova, Y. V., Ershova, I. G., \& Plotnikov, V. A. (2013). Educational System Influence on Knowledge Economy Formation. World Applied Sciences Journal, 27(5), 679-683.

\section{Copyrights}

Copyright for this article is retained by the author(s), with first publication rights granted to the journal.

This is an open-access article distributed under the terms and conditions of the Creative Commons Attribution license (http://creativecommons.org/licenses/by/3.0/). 